\title{
periferio
}

\section{CINEMA NA EDUCAÇÃO DE JOVENS E ADULTOS COM DEFICIÊNCIA INTELECTUAL: UMA RELAÇÃO POSSÍVEL}

\author{
Kelly Maia Cordeiro ${ }^{1}$ \\ SME Angra dos Reis-RJ \\ Mirna Juliana Santos Fonseca ${ }^{2}$ \\ Pontifícia Universidade Católica - Rio de Janeiro
}

\section{Resumo}

0 artigo apresenta reflexões sobre uma pesquisa que traz o cinema para o contexto de escolarização e vida de jovens e adultos com deficiência intelectual e analisa os processos que incidem nessa relação. Os sujeitos são estudantes de uma unidade de atendimento especializado ligado à rede municipal de ensino de Angra dos Reis-RJ, que assistiram a três filmes no cinema local e participaram de debates após as sessões. Os dados analisados são oriundos das gravações dos debates e dos diários de campo que auxiliaram no registro dos acontecimentos e do contexto das atividades dentro e fora da escola. A pesquisa está embasada nos pressuposto da perspectiva histórico-cultural de Vygotski, tem como metodologia a pesquisa-ação, utilizando a análise de conteúdo para criação de categorias analíticas. Os resultados indicam que: a experiência com cinema não era recorrente para os sujeitos da pesquisa; a deficiência é apresentada como justificativa para a ausência desse encontro na vida dos estudantes, sendo, mesmo que inconscientemente, um estigma para eles; o contexto do cinema possibilita uma aprendizagem coletiva entre os participantes, oportunizando aos envolvidos (estudantes e professora) novos modos de ensinar e de aprender. 0 artigo, portanto, abre uma discussão ainda pouco explorada no campo de cinema e educação e busca alargar os olhares para a educação especial, ao indicar que o cinema apresenta-se como caminho profícuo para o desenvolvimento social e cognitivo de estudantes com deficiência intelectual.

Palavras-chave: aprendizagem; cinema e educação; deficiência intelectual; jovens e adultos

\footnotetext{
1 Mestra em Educação pela Universidade Federal do Estado do Rio de Janeiro (UNIRIO). Professora da Rede Municipal de Ensino de Angra dos Reis-RJ. Atua como pesquisadora associada ao grupo de pesquisa Observatório de Educação Especial e Inclusão Educacional (ObEE/UFRRJ), vinculado ao Programa de Pós-Graduação em Educação da Universidade Federal Rural do Rio de Janeiro (UFRRJ). kelly05maia@gmail.com

2 Doutoranda em Educação pela Pontifícia Universidade Católica do Rio de Janeiro (PUC-Rio) com bolsa Capes ProEx, é pesquisadora do Grupo de Pesquisa em Educação e Mídias (Grupem), vinculado ao Programa de Pós-Graduação em Educação dessa instituição. Mestra em Educação pela UNIRIO. mirnajuliana@gmail.com
} 


\section{periferio}

\section{CINEMA IN THE EDUCATION OF YOUNG PEOPLE AND ADULTS WITH INTELLECTUAL DISABILITY: A POSSIBLE RELATIONSHIP}

\section{Abstract}

The article presents reflections about a research that brings the cinema to the context of schooling and life of young people and adults with intellectual disability and it analyzes the processes that affect this relationship. The subjects are students of a specialized care unit, who watched three films in the local cinema and participated in debates after the sessions. The datas analyzed come from recordings of the debates and the field diaries that helped to register the events and the context of the activities inside and outside of school. The research is based on the assumption of the historicalcultural perspective of Vygotski. It has as methodology the action research, it uses content analysis for the creation of analytical categories. The results indicate that: the experience with cinema was not recurrent for the subjects of the research; The desability is presented as justification for the absence of this encounter in the life of the students and this is even though unconsciously, a stigma for these subjects; The context of cinema allows a collective learning among the subjects, giving the participants new ways of teaching and learning. Therefore, the text opens an issue not explored in the field of cinema and education and it seeks to broaden studies for special education by pointing out that cinema at school can modify the ways of learning and teaching also of students with intellectual disabilities.

Keywords: learning; cinema and education; intellectual disability; young people and adults 


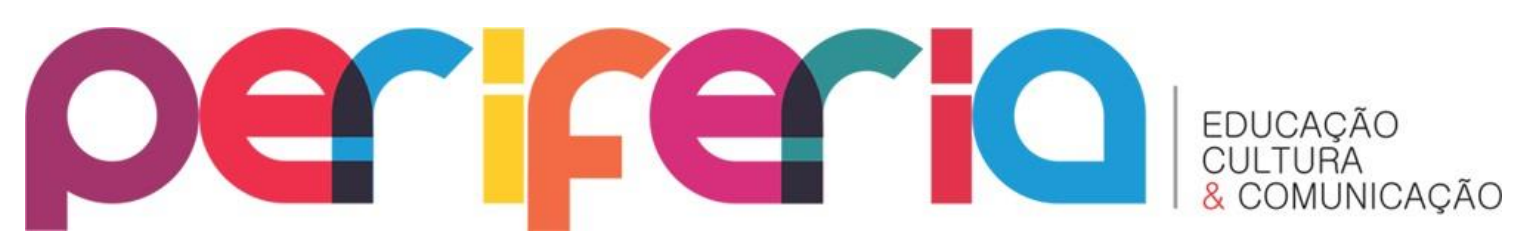

\section{INTRODUÇÃO}

"Se o encontro com o cinema como arte não
ocorrer na escola, há muitas crianças para as
quais ele corre o risco de não ocorrer em
lugar nenhum."
Alain Bergala (2008, p. 33)

A epígrafe deste texto é uma frase bastante conhecida pelos pesquisadores do campo de cinema e educação, retirada da obra "A hipótesecinema”, do cineasta francês que auxiliou na implantação de um projeto de cinema nas escolas de seu país, entre os anos 2000-2005. Essa frase pode ser considerada uma "máxima" para os estudiosos desse tema e, embora já propagada em diversos textos e projetos, resolvemos iniciar este artigo com ela, uma vez que para o público da educação especial ela é ainda mais forte. Bergala (2008) refere-se à realidade francesa de alunos que podem não ter contato com o cinema se a escola não lhes apresentar essa arte. Este artigo trata da experiência proporcionada a uma turma de jovens e adultos com deficiência intelectual (DI), em atividades com filmes, nas quais buscamos nos guiar pelas ideias desse autor e seus interlocutores do campo de cinema e educação, propiciando aos estudantes com DI esse encontro com a arte do cinema. Podemos afirmar, mesmo neste início de conversa, com base nos resultados desta pesquisa, que se a experiência com o cinema para estudantes não deficientes pode deixar de acontecer se a escola não promovê-la, esse encontro pode ser ainda mais improvável ao tratarmos de pessoas com DI.

Ao longo da história da humanidade, como explicam Mendes (2006), Omote (1996) e Piccolo (2012), a sociedade optou pela segregação e isolamento das pessoas com deficiência, na busca de torná-las "invisíveis". Tais condutas visavam evitar que esses sujeitos causassem "problemas", levando-os ao confinamento no lar ou em instituições criadas para esse fim. De acordo com Januzzi (1992) e Mazzota (1996), o que estava presente nos discursos e nas ações vigentes à época, era o controle em manter a ordem social, e quando se voltavam ao campo educacional, o que se via, em primeiro 


\section{periferio}

plano, era o interesse em tornar as pessoas com deficiência produtivas de alguma forma para o mercado de trabalho.

Mas o que o campo de cinema e educação tem a ver com isso? Essa não é uma relação nova, mas imbricada numa série de questões. Estamos mais acostumados a pensar nessa relação pelas narrativas fílmicas, tendo a pessoa com deficiência como personagem ou sendo o foco de debates dentro do contexto dos filmes. Os filmes que tratam da temática da deficiência geralmente enfatizam esse estigma nos personagens para fazer o espectador refletir sobre questões como: a deficiência, a tolerância e o respeito ao outro. Não objetivamos entrar no mérito de análise dos filmes, nem sobre as narrativas cinematográficas a respeito dessa temática, mas destacamos que esse aspecto já vem sendo levantado em pesquisas no campo de cinema educação. Teixeira e Grammont (2016), por exemplo, exploram um pouco essa questão a partir da análise de 130 filmes, iniciando no ano de 1931, com a obra de Charlie Chaplin, até 2014, com os filmes Hoje eu quero voltar sozinho e A família Bélier.

O que propomos como ação na escola, vai além desse olhar. Autoras como Fantin (2011), Fresquet (2013) e Duarte (2009) discorrem sobre a possibilidade de a escola ser fomentadora de práticas com o cinema, que conduzam o educando para além da mera interpretação das narrativas, mas pelo entrelaçamento de práticas diversas, a partir do potencial para a socialização de que é prenhe o cinema. Ao refletir sobre essa questão, Fantin (2011, p. 114) afirma que:

O cinema é um grande agente de socialização que possibilita encontros das mais diferentes naturezas: de pessoas com pessoas na sala de exibição, das pessoas com elas mesmas, das pessoas com as narrativas nos filmes, das pessoas com as culturas nas diversas representações fílmicas e das pessoas com imaginários múltiplos, etc.

Esse ponto de vista interliga-se com a questão da inclusão da pessoa com deficiência. É papel da escola possibilitar a todos os educandos 


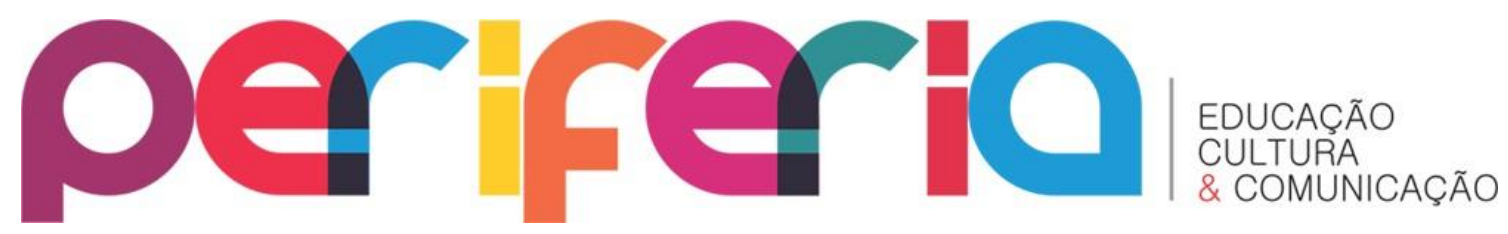

oportunidades de experienciar diferentes práticas culturais, entre elas o cinema, com o qual realizamos uma intervenção direta junto a jovens e adultos com $\mathrm{DI}$, que frequentam o atendimento educacional especializado (AEE) ligada à rede municipal de educação de Angra dos Reis-RJ, conforme apresentamos neste artigo.

O projeto que deu origem a este artigo teve início neste ano de 2017, vendo no cinema a oportunidade de trabalhar, além da inclusão social, a inclusão educacional desses estudantes, tendo como objetivo: trazer o cinema para o contexto de vida de jovens e adultos com DI e construir uma relação de aprendizado através dessa arte. Duarte $(2009$, p. 61) afirma que diante de um filme somos todos impactados de alguma forma, ressaltando que:

\begin{abstract}
Apesar de mais sofisticados, do ponto de vista da atividade intelectual, conhecimentos escolares e/ou acadêmicos não parecem ter um peso maior do que os demais recursos utilizados na interpretação que fazemos de um filme quando estamos em contato com ele. Nesse momento (e talvez somente nesse), a "magia" do cinema parece nos atingir a todos do modo mais ou menos semelhante. Quero dizer com isso que, quando nos dispomos, de fato, a ver um filme, somos seduzidos, por ele, independentemente do nosso grau de escolaridade.
\end{abstract}

Os jovens e adultos dessa unidade têm pouca experiência com o cinema, mas muitas histórias de vida relacionadas ao fracasso escolar, que predominantemente tem seu foco na aprendizagem de conceitos científicos. Vygotski (2012) enfatiza a importância da colaboração e das atividades coletivas, principalmente para pessoas com deficiência:

Na relação social se produz uma espécie de serviço mútuo. 0 que é intelectualmente mais dotado adquire a possibilidade de manifestar sua atividade social com respeito ao que é menos dotado e ativo. Este último, por sua vez, extrai da comunicação social com o mais ativo aquilo que todavia lhe resulta inacessível, o que com frequência constitui um ideal inconsciente ao que tende a criança intelectualmente deficiente. (VYGOTSKI, 2012, p. 224). 


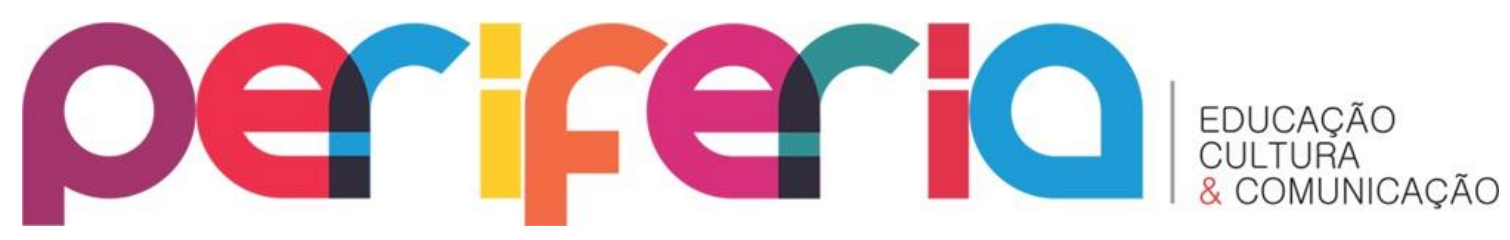

Nesse sentido, desenvolver essa pesquisa significa também, a possibilidade de aprendizado ampliado de um bem cultural e social. Vivemos em uma sociedade amplamente impactada pelo audiovisual, em que cada ícone carrega um significado, um propósito, uma intenção, sem isenção de neutralidade e numa perspectiva de leitura rápida pelos sujeitos. Compreendemos que se faz necessário educar e ampliar o olhar dos educandos para a leitura audiovisual, ainda mais se estamos nos referindo a um público cujo suporte principal de acesso e circulação social se dá em maior proporção pela leitura das imagens que circulam diariamente por todo lugar.

Bergala (2008) sugere experimentar o cinema como ato criativo e hipótese de alteridade, no encontro com o outro e com a arte, por meio da expressão de sentidos e ações desprendidos das tendências normatizadoras, e afirma:

A arte não pode depender unicamente do ensino, no sentido tradicional de disciplina inscrita no programa e na grade curricular dos educandos, sob a responsabilidade de um professor especializado recrutado por concurso, sem ser amputada de uma dimensão essencial. A hipótese extrai sua força e sua novidade da convicção de que toda forma de enclausuramento nessa lógica disciplinar reduziria o alcance da arte e sua potência de revelação, no sentido fotográfico do termo. A arte, para permanecer arte, deve permanecer um fermento de anarquia, de escândalo, de desordem. A arte é por definição um elemento perturbador dentro da instituição. (p. 29-30).

Juntamente com Fresquet (2007), Bergala (2008) nos desafia a romper com paradigmas consolidados tanto na educação quanto na arte e no cinema comercial, nos fortalecendo a abrir espaços para pensar a relação entre cinema e educação, à medida que, enquanto protagonistas da educação e pesquisadores, possamos atuar e propor outro fazer. Ao trazer o cinema enquanto arte, ato criativo e alteridade, expressamos o nosso olhar, movemos nossos sentidos e nos encontramos com o outro, construindo e reconstruindo a cada processo do fazer. 


\section{periferio}

\section{PROCEDIMENTOS METODOLÓGICOS}

Este estudo foi desenvolvido com base na pesquisa qualitativa. Minayo (2006) distingue esse tipo de pesquisa a partir de cinco fases: a fase inicial, exploratória; o trabalho desenvolvido no campo; o tratamento do material coletado; a teorização sobre os dados; e o resultado.

A pesquisa-ação foi nossa opção, devido, fundamentalmente, a dois fatores: primeiro, pela proximidade de uma das pesquisadoras com os sujeitos da pesquisa, coordenando a execução do trabalho, e segundo pelo fato de que os pressupostos da pesquisa-ação preveem essas ações e as consideram favoráveis e positivas no grupo. Para Thiollent (2005, p. 16):

A pesquisa-ação é um tipo de pesquisa social com base empírica que é concebida e realizada em estreita associação com uma ação ou com a resolução de um problema coletivo e no qual os pesquisadores e os participantes representativos da situação ou do problema estão envolvidos de modo cooperativo ou participativo.

0 autor considera que os passos da pesquisa-ação devem ser bem definidos e preparados, pois são previstas alterações durante o processo. Estando o pesquisador envolvido na execução, precisa estar ciente de cada etapa, estar apto a propor encaminhamentos, através de uma rápida verificação do momento, quando houver a necessidade.

Nesse sentido, os instrumentos metodológicos contribuem como um aporte ao que acontece no campo. Nesta pesquisa, optamos por assistir a um filme no cinema, registrando em diário de campo as observações desse momento e gravando em áudio as conversas posteriores à exibição dos filmes, geralmente realizadas no primeiro reencontro com os estudantes após a ida ao cinema, inserido na organização de atendimento da própria unidade escolar. Nessa prática, as conversas são realizadas em grupos, com no mínimo dois estudantes e no máximo cinco. Utilizamos o trailer do próprio filme, 


\section{periferio}

disponibilizado na internet, como disparador da discussão, que é mediada pela pesquisadora. As observações desses momentos também foram registradas no diário de campo, com relatos como: "por vezes, eles pedem para repetir a exibição do trailer"; "Breno ${ }^{3}$ comenta o trailer durante a exibição"; "Luana e Carlos ficam em silêncio e praticamente imóveis na exibição do trailer" (Trecho do diário de campo sobre o filme Quatro vidas de um cachorro). As conversas duram em média 90 minutos, dependendo do grupo e do tempo que cada um deles tem de retorno às questões.

Para estudar esses dados, utilizamos a análise de conteúdo, que enfatiza a informação obtida pela fala humana ou por mensagem transmitida por elementos verbais ou não verbais, pois "expressam as representações sociais na qualidade de elaborações mentais construídas socialmente, a partir da dinâmica que se estabelece entre a atividade psíquica do sujeito e o objeto do conhecimento." (FRANCO, 2008, p. 12). O ponto central da análise de conteúdo é a criação das categorias, definidas a partir de uma leitura flutuante do material de campo. Procuramos pelas convergências e divergências do que foi descrito nos diários de campo de observação durante as sessões, da transcrição das conversas após exibição do filme e diário de campo desses momentos, com os objetivos propostos para a pesquisa. Em seguida, passamos para descrição e análise das categorias elencadas.

Os sujeitos da pesquisa são jovens e adultos com DI, de uma unidade de AEE específica para esse público, localizada em Angra dos Reis. Nessa unidade estão matriculados educandos da educação especial de diferentes bairros e sua proposta de trabalho pedagógico está voltada a desenvolver habilidades para a vida adulta mais autônoma e independente, do qual fazem parte atividades fora da unidade, como ida à praia ou ao cinema, por exemplo.

A participação dos jovens e adultos no cinema foi um convite aos dois grupos que frequentavam a unidade pela manhã e tarde. A participação dos

\footnotetext{
${ }^{3}$ Os nomes utilizados aqui são fictícios, a fim de resguardar a identidade dos sujeitos envolvidos na pesquisa.
} 


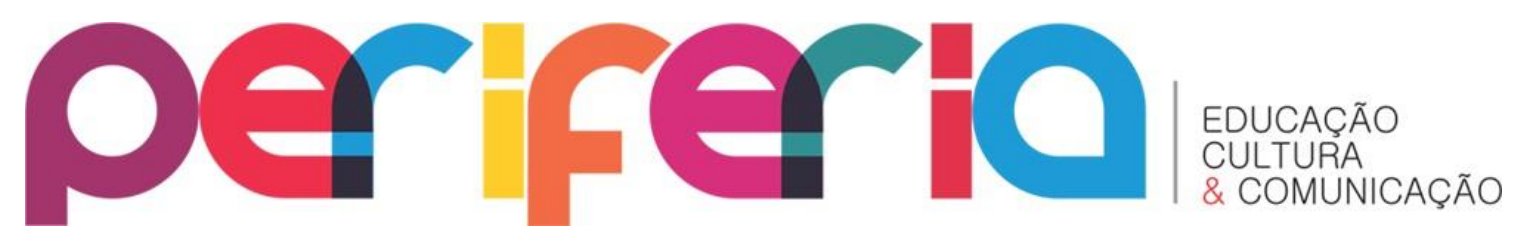

responsáveis nas atividades externas é sempre um convite na intenção de ampliar a participação dos educandos, uma vez que nem todos têm autonomia individual de circular pela cidade. Mesmo estes não sendo sujeitos da pesquisa, a presença e algumas das interações acabam sendo também, ponto de escuta que incidem sobre o objetivo da pesquisa.

0 número de participantes nas atividades propostas pela pesquisa não é fixo. Do total de 16 inscritos, 8 participaram de duas sessões, 2 participaram das três sessões e 6 participaram apenas de uma sessão. Ao serem questionados sobre o motivo de não terem participado: um disse que o som alto incomodou; 3 são irmãos e um deles estava doente na ocasião, por isso a avó achou melhor não ir nenhum deles; um informou não ter o dinheiro para pagar a entrada; e um não informou o motivo.

Neste artigo, serviram de base os dados coletados em três sessões no cinema para assistir aos filmes: Quatro vidas de um cachorro, A Bela e a Fera e Mogli: o menino lobo. Estes dois últimos têm enredo conhecido do grande público e suas histórias são oriundas dos clássicos da literatura. A nosso ver, novidade e o que desperta o interesse, nessa refilmagem, é o emprego da tecnologia definida como live-action, que significa a combinação da animação, tão conhecida nos desenhos, por exemplo, com atores reais. É um formato que busca chegar mais próximo da realidade, empregando efeitos especiais para isso. Nessa perspectiva, o filme se apresenta com uma "novidade", voltada para um público para além do infantil.

A partir desse aspecto que evidencia o som e a imagem, o debate sobre os filmes se ampliam para além da narrativa, constituindo-se em processos de aprendizagens significativas da e sobre a tecnologia. Kenski (2007) afirma que as transformações da tecnologia podem contribuir com as formas de ensinar e de aprender que se encontram na escola e fora dela. A sociedade está impregnada pela cultura digital, na mais tenra idade e independente das condições da deficiência, o que percebemos são os usos cada vez mais recorrentes de dispositivos móveis de interação e comunicação, todos eles com acesso a materiais audiovisuais em diversos formatos. 


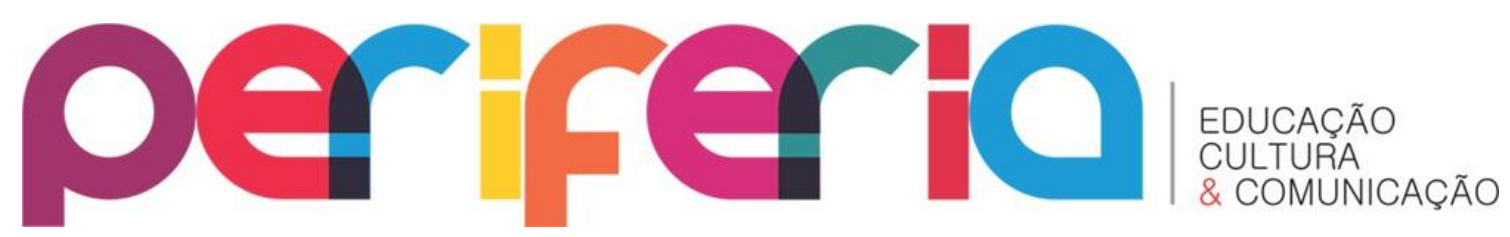

A escolha dos filmes sempre é um processo cuidadoso, sendo um desafio encontrar filmes que interessem aos jovens e adultos da pesquisa por sua qualidade, sem apresentar legendas, pois os estudantes não dominam a leitura. Fantin (2011, p. 140) elenca quatro critérios para essa escolha:

\begin{abstract}
Ampliar o repertório cultural, assegurando filmes que apresentem a diversidade de contextos socioculturais, de linguagens, de valores e estéticas. Considerar que todo filme pode ser educativo a partir da relação que se estabelece com ele, mesmo considerando "qualidades inerentes" que certos filmes possuem. Considerar os níveis de desenvolvimento e o conhecimento que se tem das crianças: interesses, capacidades e preferências relacionadas ao capital cultural, às condições de infância, às capacidades reais e potenciais, idade, gênero, classe, etnias etc. Considerar o grau de abertura e incerteza que os filmes possuem, de forma a permitir interpretações diversas.
\end{abstract}

As considerações da autora nos auxiliam ao avaliarmos o conteúdo e a grade de horário dos filmes ofertados no cinema local e percebemos que além do formato mais conhecido comercialmente, seria interessante que 0 estabelecimento ofertasse outros formatos e horários mais flexíveis. Ambos os fatores contribuíram para não mantermos a regularidade que gostaríamos de frequência ao cinema.

Compartilhamos com Migliorin (2014, p. 10) o convite que o cinema faz ao nos oferecer os filmes para assistirmos e discutirmos sobre ele: "é para que habitemos o melhor e o pior dos mundos, e, felizmente, o espectador existe, não é um 'assujeitado', mas alguém presente." Nesse sentido, buscamos construir com os jovens e adultos com $\mathrm{DI}$ o gosto pelo cinema e pela linguagem cinematográfica.

A partir do contexto explicitado, surgiram algumas categorias de análise e escolhemos três delas para tratar neste artigo: o estigma que a deficiência por vezes traz para esses sujeitos; o encanto pelo cinema; e o cinema e educação para esse público em específico. 


\section{periferio}

\section{QUANDO A DEFICIÊNCIA DEIXA MARCAS NO SUJEITO}

Atualmente, as salas de cinema localizam-se em shoppings e o marketing em torno dos filmes, pelo menos os mais comerciais, circulam por várias mídias, agregando valor de consumo em busca de mais espectadores. Quanto mais facilitado o acesso e mais divulgado o serviço, mais público podese ter. Nessa lógica, entendemos que o cinema não é uma novidade. Assim, procuramos dialogar sobre os sentidos construídos socialmente através do relato inicial das mães dos educandos da pesquisa, quando afirmaram que tinham receio (hipotético) da reação dos filhos dentro do cinema, citando a escuridão, o som alto, ou mesmo por acharem que as manifestações esfuziantes dos demais espectadores poderiam levar seus filhos a ficarem impressionados com o filme e até mesmo entrarem em comportamento variado. Tal fato evidencia que o impedimento ao cinema, até aquele momento, não se deu por questões econômicas ou de dificuldade no acesso, e sim pela questão da deficiência, como condição determinante de inserção em práticas culturais, o que se configura na contramão da inclusão social.

De acordo com Piccolo (2012), a construção social sobre a deficiência, na forma como essas pessoas são interpretadas e retratadas, se desenha a partir do contexto social da época, ganha força pelos estudos das diferentes áreas do conhecimento e pelo ativismo em luta de causas do gênero. Por muitos anos, a visão clínica da deficiência foi determinante para a vida desses sujeitos, deixando-os em condições inferiorizadas, de exploração, privação e sem a liberdade de expressão. 0 autor relata a extrema pressão da área médica, no século XIX, sobre as pessoas com deficiência, quando havia uma urgência de analisar e classificar o que estava desalinhado em relação aos padrões da época, segregando-as em internatos para viverem confinadas. Transcorrendo pela visão religiosa, mística e etérea, chegando à visão científica, no terreno da biologia e medicina, todas desconsideravam o ambiente como transformador das relações humanas e mantinham a opressão, discriminação e o estigma como prerrogativas às pessoas com deficiência, 


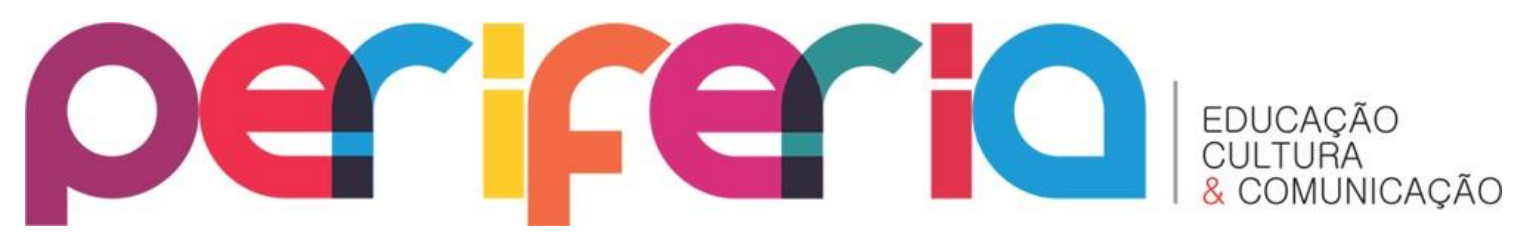

sendo esta impressa como uma segunda pele da pessoa. Dessa forma, o peso do estigma fica latente em diferentes situações, como a referendada pelas mães de educandos com DI. Para Goffman (1963, p. 11):

A característica central da situação de vida, do indivíduo estigmatizado pode, agora, ser explicada. É uma questão do que é com frequência, embora vagamente, chamado de "aceitação". Aqueles que têm relações com ele não conseguem the dar o respeito e a consideração que os aspectos não contaminados de sua identidade social os haviam levado a prever e que ele havia previsto receber; ele faz eco a essa negativa descobrindo que alguns de seus atributos a garantem.

O estigma torna-se parte do contexto de vida desses sujeitos, controlando e restringindo suas ações. O conceito é originário da Grécia antiga para identificar as marcas físicas do corpo, e vem sendo apontado por Goffman (1963) como um atributo socialmente incorporado às pessoas que são diferentes, geralmente de grupos minoritários que constituem a sociedade, sendo estes os mais propensos a serem estigmatizados. Nem sempre percebemos que estamos reforçando a condição de estigmatizado, pois são anos de práticas cristalizadas que enfatizam essa condição em busca do controle e da ordem social.

A deficiência vista por um único prisma, de forma isolada ou sem aprofundamento, tende a se tornar incompleta, parcial e homogeneizante em uma categoria. Caminhando para uma percepção sobre a deficiência de uma forma mais ampliada, na área educacional, autores como Omote (1996), Pletsch (2009), Glat (2011) e Mendes (2006) compreendem que as pesquisas dessa temática não podem estar desvinculadas do contexto das relações sociais. Cabe à sociedade reestruturar seus modos e formas, adequando os espaços em direção à inclusão. Nos pressupostos contidos na Política Nacional de Educação Especial na Perspectiva de Educação Inclusiva (BRASIL, 2008), o que se busca é o direito ao acesso à educação, ao aprendizado e à participação, prevalecendo as adequações físicas e curriculares, necessárias 


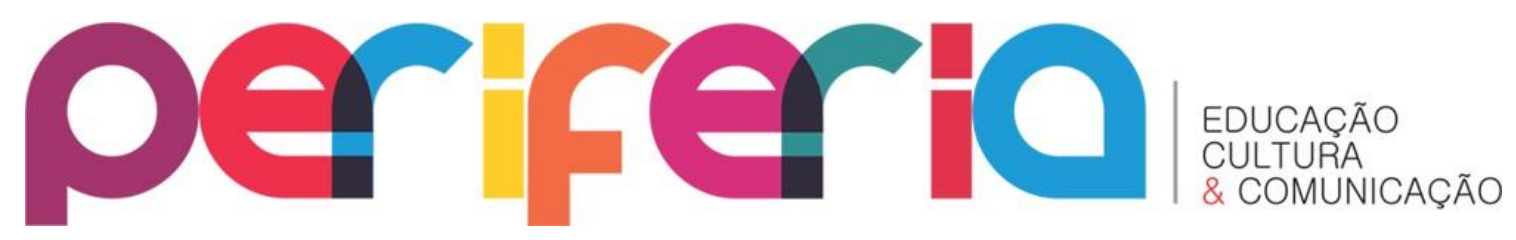

para atingir esses objetivos.

Kassar (2016, p. 1231) discorre sobre as políticas educacionais adotadas no Brasil, alinhadas à escola como espaço de desenvolvimento humano: “Embora seja inegável a importância da educação na vida das pessoas, o que ressaltamos é que a perspectiva que vem sustentando as políticas educacionais não induz à garantia de um processo educativo adequado nas escolas." O que pauta as políticas educacionais são os resultados pelos índices; já no entendimento de desenvolvimento humano, dentro da perspectiva histórico-cultural, as relações de ensino-aprendizagem se constroem pelas práticas sociais e a escola é a fomentadora dessas práticas, com ações motivadoras e reflexivas, considerando a diversidade dos sujeitos.

\section{QUANDO O CINEMA QUEBRA BARREIRAS E ENCANTA}

A possibilidade de estar no cinema pode parecer algo trivial para aqueles que estão acostumados com essa experiência desde a infância. Essa não é uma realidade para pessoas com DI, conforme percebemos na sessão do filme Quatro vidas de um cachorro:

Assim que saímos do cinema, a maioria pediu para ir ao banheiro. Eu estava na porta deste, quando o Jonas passou correndo, indo em direção às lojas do shopping. Pedi a Breno que fosse atrás dele, e procurei Antônio para fazer o mesmo. Quando retornou, Antônio explicou que Jonas saiu correndo de euforia. Era a primeira vez dele no cinema e, por isso, ficou muito contente. A irmã dele, Gisele, também chorou de emoção. Era a primeira vez no cinema para os três irmãos: João, Gisele e Jonas. (Trecho do diário de campo).

Esse relato da pesquisa trata de outras marcas, mas não aquelas atribuídas aos sujeitos com DI por outras pessoas, como tratamos na análise anterior. São as marcas que a experiência do cinema deixa nos sujeitos que se permitiram passar por essa experiência. No caso relatado acima, a narrativa fílmica não foi o mais relevante para os irmãos, sendo destacado pelo colega 


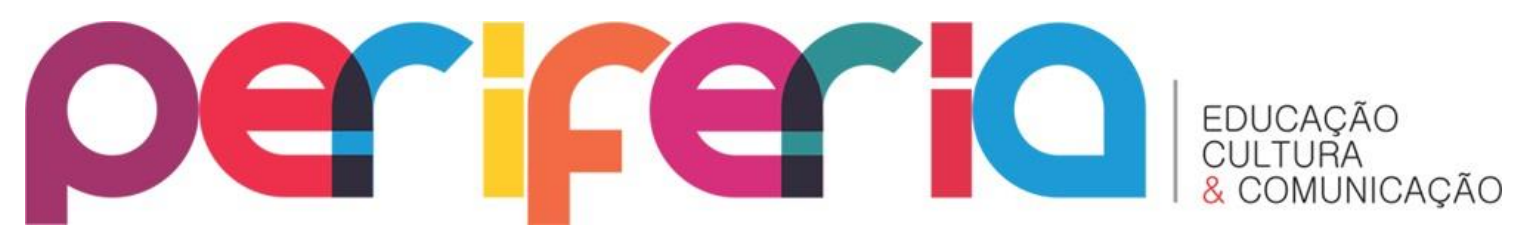

que o estar no cinema era o que mais havia lhes tocado. Larrosa Bondía (2002) nos convida a pensar a educação a partir do conceito de experiência e é com base nessa discussão que buscamos entender o sentido que a experiência do cinema teve entre os sujeitos pesquisados, uma vez que Jonas correu de euforia e Gisele chorou de emoção nesse primeiro contato com o cinema. Para Larrosa Bondía (2002, p. 21):

A experiência é o que nos passa, o que nos acontece, o que nos toca. Não o que se passa, não o que acontece, ou o que toca. A cada dia se passam muitas coisas, porém, ao mesmo tempo, quase nada nos acontece. Dir-se-ia que tudo o que se passa está organizado para que nada nos aconteça.

O sair da unidade de estudos para um espaço diferenciado, junto com os colegas para assistir a um filme numa sala escura e em tela grande foi uma experiência significativa de alteridade para esses sujeitos, como defendem Bergala (2008), Fantin (2011) e Fresquet (2013), uma vez que é estabelecida naquela experiência uma relação com os colegas e professores, com o espaço, e com o filme. Confirmamos, assim, o que diz Bergala na epígrafe deste artigo: sem a escola, alguns participantes desse grupo de jovens e adultos correriam o risco de jamais ter um contato com o cinema.

Surge, então, a pergunta: por que Jonas e seus irmãos nunca estiveram no cinema? Entre as inúmeras respostas possíveis, podemos levantar o fato deles não "entrarem nos moldes" de espectadores esperados para esse tipo de atividade. Alguns pais comentaram conosco que não levavam seus filhos ao cinema por medo de não se adaptarem à sala escura ou ao som demasiadamente alto de algumas cenas, como já apresentamos. Assim, para que possam experimentar outros ambientes e atividades, esses sujeitos dependem de responsáveis que permitam esse movimento em direção a novas experiências - o que requer arriscar-se frente à reação desconhecida do outro. De acordo com o filósofo, sem a exposição não há experiência: 


\section{periferio}

Do ponto de vista da experiência, o importante não é nem a posição (nossa maneira de pormos), nem a "o-posição" (nossa maneira de opormos), nem a "imposição" (nossa maneira de impormos), nem a "proposição" (nossa maneira de propormos), mas a "exposição", nossa maneira de "expormos", com tudo o que isso tem de vulnerabilidade e de risco. [...] É incapaz de experiência aquele a quem nada the passa, a quem nada the acontece, a quem nada the sucede, a quem nada o toca, nada lhe chega, nada o afeta, a quem nada o ameaça, a quem nada ocorre. (LARROSA BONDÍA, 2002, p. 25).

Correr o risco faz parte da experiência com o cinema na escola, como compreende Migliorin (2011, p. 134), uma vez que "o cinema não pede nada, apenas aconchega as capacidades sensíveis dos sujeitos comuns." Estar em contato com o não saber que traz o cinema para a escola é um terreno movediço em que muitos responsáveis e professores preferem não se arriscar. Acreditamos ser preciso experimentar e permitir essa experiência a esses sujeitos, afinal: "O cinema não se encontra na escola para ensinar algo a quem não sabe, mas para inventar espaços de compartilhamento e invenção coletiva, colocando diversas idades e vivências diante das potências sensíveis de um filme." (MIGLIORIN, 2011, p. 134).

\section{APRENDIZAGEM E CINEMA NA ESCOLA}

A aprendizagem de pessoas com deficiência é sempre algo que suscita muitas posições diferenciadas. No campo da deficiência, um tipo de deficiência não é condição determinante para a outra, uma vez que há variações dentro de uma mesma tipologia de deficiência. Mas é fato que as diferentes deficiências demandam ações diferenciadas de atendimento e metodologia educacional.

Nem todos os jovens e adultos desta pesquisa são alfabetizados, porém todos têm uma trajetória escolar e de vida a serem consideradas. No contexto da aprendizagem, as contribuições de Vygotski (2012, p. 187) mostram que o desenvolvimento cultural é a “principal esfera em que é possível compensar a 


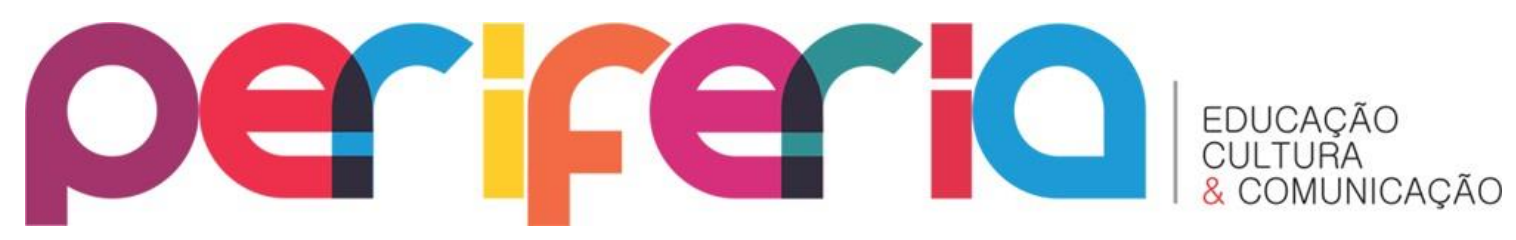

deficiência. Onde não é possível avançar no desenvolvimento orgânico, abrese um caminho sem limites para o desenvolvimento cultural", o que nos permite pensar em intervenções possíveis na aprendizagem desses sujeitos, partindo também da relação com os filmes.

Apostamos que a experiência com cinema pode contribuir para $o$ desenvolvimento de aprendizagens, tanto dos conceitos científicos preconizados pela escola, quanto de conhecimentos para viver em sociedade. De acordo com Pletsch (2014), as pessoas com DI têm muito potencial de aprendizagem a ser desenvolvido, o estigma que carregam socialmente é que muitas vezes criam barreiras para o seu aprendizado.

O modo como enxergamos o aluno e as expectativas que temos sobre ele acaba impactando nas práticas que dirigimos para eles e, consequentemente, no seu desenvolvimento. [...] Mas, é preciso ter clareza que para trilhar outros caminhos de desenvolvimento faz-se necessário oferecer ao sujeito com deficiência intelectual condições sociais e educacionais para tal. (PLETSCH, 2014, p. 11).

A partir dessas considerações, a teoria da aprendizagem de Vygotski (2012) pode corroborar com os estudos do cinema e educação, como interseção possível na escolarização de pessoas com DI. O conceito de mediação parte do princípio que a interação com o outro e com artefatos da cultura, no conhecimento partilhado, são aprendidos "através da interiorização dos meios de operação das informações, meios estes historicamente determinados e culturalmente organizados, que a natureza social das pessoas tornou-se igualmente sua natureza psicológica." (VIGOTSKI; LURIA; LEONTIEV, 2016, p. 31). Ou seja, os processos naturais, característicos da infância vão se transformando em processos psicológicos instrumentais mais complexos, por meio das diferentes interferências que o sujeito tem com as questões culturais. Portanto, a aprendizagem se apresenta antes da entrada do sujeito na escola. Para Vigotski, Luria, Leontiev (2016, p. 116): 


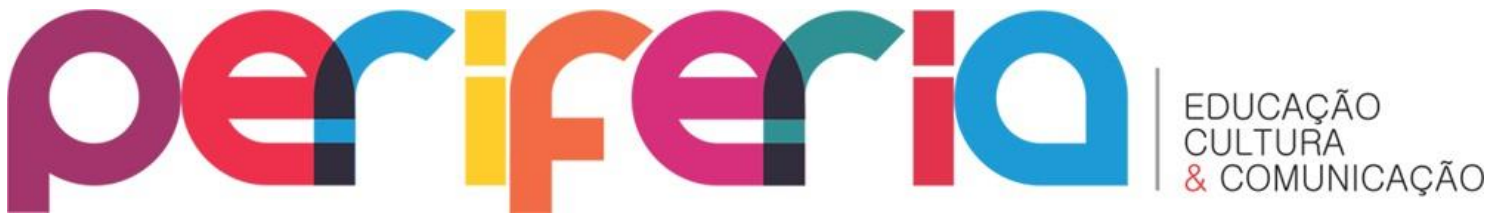

[...] a aprendizagem escolar orienta e estimula processos internos de desenvolvimento. A tarefa real de uma análise do processo educativo consiste em descobrir o aparecimento e o desaparecimento dessas linhas internas de desenvolvimento no momento em que se verificam, durante a aprendizagem escolar.

Avançando no papel docente enquanto mediador dos processos de aprendizagem, compreendemos que as práticas pedagógicas apoiadas nas experiências com filmes podem representar significativo avanço na construção de conceitos científicos e na qualidade de vida desses sujeitos, pois a proposta recai sobre os processos e não sobre o produto.

No debate sobre o filme A Bela e a Fera, avançamos na percepção dos estudantes sobre aspectos referentes à produção fílmica, para além da narrativa:

Pesquisadora: 0 que vocês perceberam sobre o som? Ele fica diferente, bem alto.

Breno: Fica mais alto.

Pesquisadora: Por que colocam essa música?

Breno: É para agradar mais ainda, ficar mais romântico ainda, para agradar mais ainda.

Em outro momento, perguntamos sobre as percepções em relação à sala de cinema:

Danilo: Tem de diferente na sala de cinema.

Breno: Para assistir ao filme tivemos que colocar o óculos... É muito maneiro lá.

Pesquisadora: 0 que tem de maneiro lá?

Danilo: Ar-condicionado.

Breno: Outra coisa, quando chegava lá, aquele gritão que ele deu, foi lá no canto. Eu estava assim, aí chegou tacou água parecia na gente. Com os óculos parecia que estava em cima da gente. O telão está lá embaixo, essa coisa do óculos, parece que vem em cima da gente.

Nesse diálogo é possível percebermos que houve fluidez na conversa entre os alunos, a partir da mediação realizada pela pesquisadora. Os alunos 


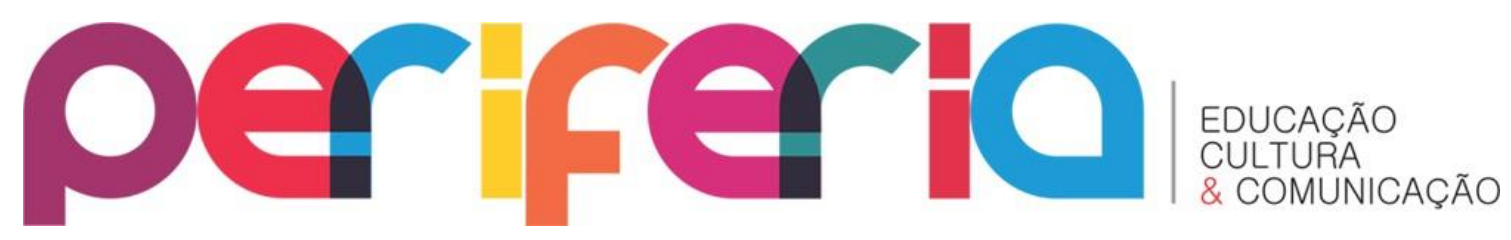

se mostraram interessados em conversar sobre o cinema, não demonstrando desatenção ou desinteresse, evidenciando o desenvolvimento cultural, como sugere Vigotski (2012) ao discorrer sobre a criança com deficiência, no conceito da compensação - o qual tem seu princípio na natureza social e sobre o desenvolvimento humano, na busca por caminhos alternativos para o aprendizado da pessoa com deficiência. E a construção desses caminhos se dá nas formas ampliadas que se constituem os processos culturais e na aprendizagem pela coletividade como fator preponderante para o desenvolvimento das funções psicológicas superiores, uma vez que: "Só no processo da vida social coletiva se tem elaborado e desenvolvido todas as formas superiores da atividade intelectual próprias do homem." (VIGOTSKI, 2012, p. 214). Quanto mais cedo a criança for inserida nesse universo coletivo, de diversidade cultural, mais rápido se apropriará dos signos circundantes desse lugar.

Nesse sentido, a rotina da ida ao cinema com os estudantes é sempre adotada e registrada nos diários de campo, sendo este instrumento de pesquisa utilizado como parâmetro de acompanhamento, relacionando o desenvolvimento dos educandos à prática de frequentar o cinema. A seguir, evidenciamos a rotina $e$, na sequência, uma anotação referente sobre a terceira sessão de cinema, em que os estudantes assistiram ao filme $A$ Bela $e$ a Fera:

Rotina: Encontrar direto no cinema (sem passar na escola); comprar os ingressos - eles entram na fila, pagam e escolhem o acento; comprar pipoca e bebida - eles entram na fila, pagam, pegam e colocam sal; entrada na sala do cinema cada um fica com seu bilhete, entrega na portaria e se dirige ao assento. Acompanhamos (profissionais da escola e pesquisadores) todo o processo e orientamos sentar no lugar marcado. (Trecho do diário de campo).

Percebemos que a rotina fluiu de forma mais natural e menos demorada. Não demoramos tanto tempo de uma sessão a outra, o que favoreceu diferentes aspectos, entre elas a memória sobre o ambiente e a prática nas ações da rotina. (Trecho do diário de campo). 


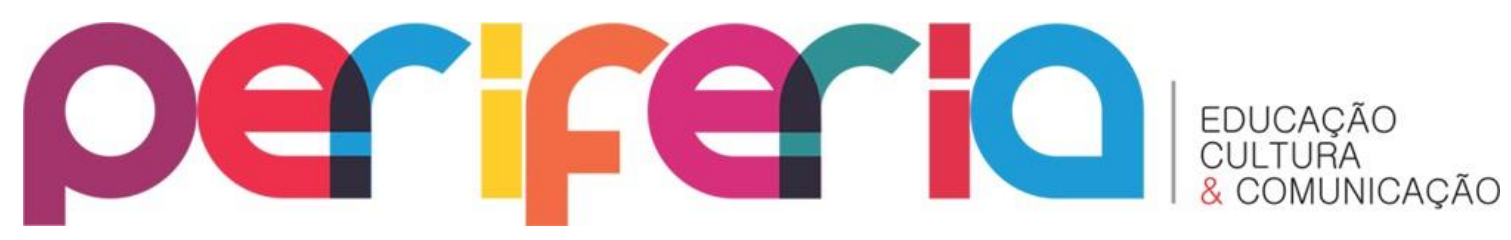

Com a frequência com que essa atividade foi realizada, podemos perceber que os jovens e adultos passaram a ter mais desenvoltura e confiança para realizar as atividades de rotina de forma mais independente. Trata-se de um ganho significativo em direção a uma vida mais autônoma. 0 aprendizado coletivo se faz presente na relação que estamos construindo com - cinema, conforme evidenciamos na fala dos sujeitos da pesquisa. Destacamos assim a forte presença da alteridade, conceito caro aos estudiosos de cinema e educação (FRESQUET, 2013; MIGIORIN, 2014), embasados em Bergala (2008), e relevante também para uma experiência sensível com os filmes e com os outros na discussão sobre estes, além de propiciar uma aprendizagem coletiva, aquela desenvolvida na troca entre os colegas e a professora, todos mediadores dessa relação horizontal de aprendizagem.

Aos poucos, os sujeitos da pesquisa começam a se apropriar dos signos pertencentes ao cinema. Como expressa o recorte do diálogo, após exibição do filme, as percepções de elementos, anteriormente não percebidos, começam a fluir no debate. Pela mediação, os jovens e adultos fazem novas relações e traçam novas hipóteses sobre o que vivenciaram e dessa maneira, “O audiovisual na escola pode afirmar esse espaço da escola como vida, descoberta, socialização de experiências e aprendizagens, para formar estudantes e professores mais esclarecidos em relação a si próprios, ao cinema e ao mundo presente, passado e futuro." (FANTIN, 2014, p. 64).

\section{RESULTADOS E CONSIDERAÇÕES FINAIS}

A pesquisa aqui apresentada buscou trazer o cinema para o contexto de vida de jovens e adultos com deficiência intelectual e construir uma relação de aprendizado por meio dessa arte. No município de Angra dos Reis há apenas um cinema, localizado em shopping, e não foi possível levar os alunos a uma sessão de filmes menos comerciais, como autores do campo de cinema educação indicam, para que crianças e jovens tenham acesso, desde a escola, 


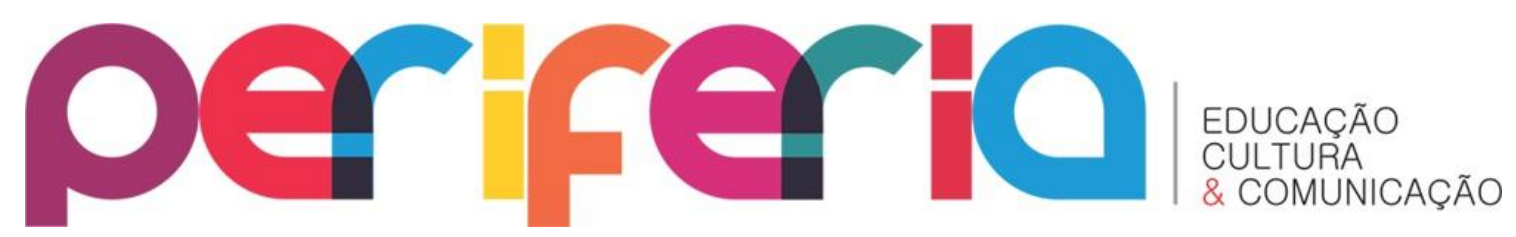

a "um leque mais amplo de opções, a fim de diversificar o gosto e as possibilidades de criação que geram o encontro de culturas, tempos e gostos pessoais." (FRESQUET, 2014, p. 69). Tal fato se dá pela própria conjuntura cultural e econômica que disponibiliza para o público, considerado como massa, apenas filmes com histórias e linguagens estruturadas dentro do roteiro pré-definido pela indústria norte-americana. Embora esse não seja o foco deste artigo, vale trazer essa ressalva para mostrar que está cada vez mais difícil ter acesso a filmes com linguagens diferenciadas e de diferentes culturas nas pequenas cidades brasileiras, mesmo que estejamos falando de um dos maiores estados desse país (de acordo com o PIB nacional). Pretendemos diversificar os filmes ofertados aos alunos quando passarmos à segunda fase da pesquisa, realizando sessões na própria escola.

Neste artigo, apresentamos e analisamos como se deu o processo de relação com o cinema e podemos destacar como resultados: o envolvimento dos sujeitos com os filmes e o espaço do cinema, a vivência de novas experiências para alguns deles, estimulando sua autoestima e a aprendizagem em relação à linguagem cinematográfica.

A partir dos pressupostos que garantem os direitos, não somente ao de acesso, mas também ao aprendizado como desenvolvimento humano, e entendendo que as práticas educativas precisam estar nessa mesma rota, destacamos a proposta desenvolvida em trazer o cinema para vida e contexto da educação desses sujeitos, incidindo tal experiência em pontos positivos para o desenvolvimento individual e coletivo deles.

Ao trazermos o contexto do cinema para dentro do AEE de deficientes intelectuais, acreditamos que essa relação é possível e viável por diferentes ângulos. Um deles é a reconfiguração de sentido sobre o aprender e a autoestima dos sujeitos envolvidos, como sinaliza Fresquet (2013, p. 61):

O cinema não requer "conhecimentos prévios". Nesse sentido, fazer cinema na escola é uma experiência rica para reduzir assimetrias entre professores e estudantes e entre eles próprios. A descoberta de novos interesses e capacidades pode 


\section{periferio}

contribuir para a uma reconfiguração da autoestima de alguns estudantes, o modo como eles são vistos pelos professores e colegas, e, inclusive, pelas próprias famílias.

A atividade de ir ao cinema possibilitou aos jovens e adultos com DI estarem e se apropriarem de um espaço social, experienciando mais um processo cultural. Além disso, a partir das interações realizadas com os participantes, no espaço do cinema e da escola, novas construções mentais de aprendizagem com o outro foram fomentadas, possibilitando aos alunos uma aprendizagem coletiva e à professora um jeito diferente de ensinar.

Outro ponto evidenciado na pesquisa é o modo como os deficientes intelectuais são vistos pela sociedade. Com a ida ao cinema, conseguimos quebrar "pré-conceitos" dos próprios responsáveis sobre as possíveis atitudes que os alunos poderiam ter ao estarem na sala escura do cinema, junto com desconhecidos e em contato com algo que não estavam habituados. Destacamos que esse foi um aprendizado relevante para vida social e cultural desses sujeitos, uma vez que muitos responsáveis perderam o medo de leválos a esse ambiente após nossas idas ao cinema.

Embora tenhamos conversado com os sujeitos sobre a linguagem cinematográfica, vale destacar que nossa proposta não está voltada para ensinar sobre cinema, mas de "educar sobre, com e através do cinema e todas as suas nuances e possibilidades." (FANTIN, 2014, p. 64). Franco (2011, p. 29) argumenta que:

A linguagem científica tem perfil analítico, descritivo, minucioso, metódico, de rigoroso vínculo com o real, procurando responder às suas demandas. Tem como finalidade mobilizar as nossas competências cognitivas de racionalidade. A linguagem artística, por outro lado, é, em todas as formas de expressão estética, uma linguagem de síntese, que resume, que reconfigura, que desconfigura, que mais indaga do que responde, que dialoga com o sonho, o devaneio e a incerteza. Busca, seja nas formas mais tradicionais como nas mais experimentais, mobilizar nossa percepção, sensibilidade e adesão afetiva, emocional, intuitiva. 


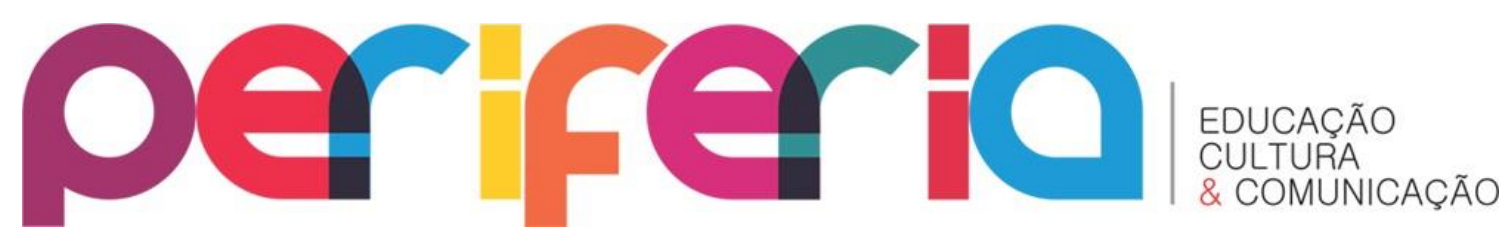

De acordo com Fresquet (2013, p. 34): “É necessário inventar, sempre, com o mundo, outros modos de habitá-lo.” Essa invenção pode ser instaurada na criação de novos mundos e outras experiências por meio do cinema para criar e inventar na escola. Reiteramos, portanto, que: “Na possibilidade de caminharem juntos, e não um contra o outro, ou um servindo de muletas para o outro é que entendemos que cinema a educação podem modificar os modos de aprender e de ensinar" (FONSECA, 2016, p. 52), mas completamos: também de alunos com deficiência intelectual. Por que não?

\section{REFERÊNCIAS}

BERGALA, Alain. A hipótese-cinema: pequeno tratado de transmissão do cinema dentro e fora da escola. Rio de Janeiro: Booklink; CINEAD-LISEFE/UFRJ, 2008.

BRASIL. Ministério da Educação. Política Nacional de Educação Especial na Perspectiva da Educação Inclusiva. Brasília, DF: SEEP, 2008.

DUARTE, Rosália. Cinema e educação. 3. ed. Belo Horizonte: Autêntica, 2009.

FANTIN, Monica. Crianças, cinema e educação: além do arco-íris. São Paulo: Annablume, 2011.

FANTIN, Monica. Audiovisual na escola: abordagens e possibilidades. In: BARBOSA, Maria Carmen Silveira; SANTOS, Maria Angélica dos. (Org.). Escritos de alfabetização audiovisual. Porto Alegre: Libretos, 2014.

FONSECA, Mirna Juliana Santos. Cinema na escola para quê? Revista Educação e Cultura Contemporânea, Rio de Janeiro, v. 13, n. 31, p. 33-55, 2016. Disponível em:

<http: / / revistaadmmade.estacio.br/index.php/reeduc/article/viewArticle/15 26>. Acesso em: 24 jun. 2017.

FRANCO, Maria Laura Puglisi Barbosa. Análise de conteúdo. Brasília: Liber Livro, 2008.

FRANCO, Marília. Hipótese-cinema: múltiplos diálogos. In: FRESQUET, Adriana (Org.). Dossiê cinema e educação \#1: uma relação sobre a hipótese de alteridade de Alain Bergala. Rio de Janeiro: UFRJ, 2011. 


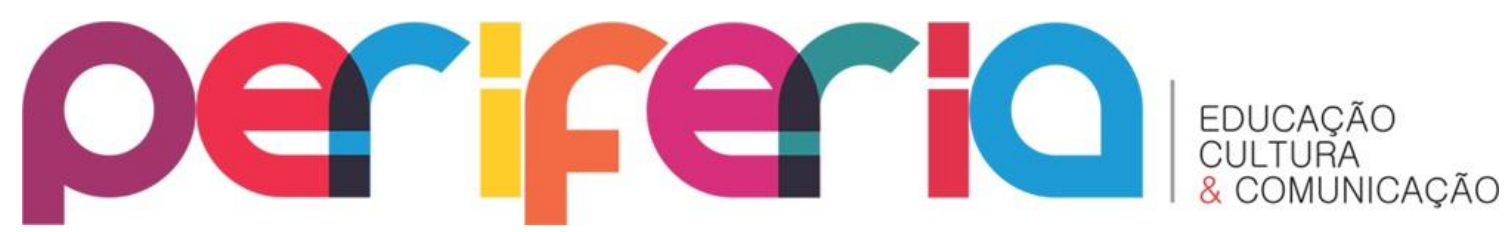

FRESQUET, Adriana (Org.). Imagens do desaprender: uma experiência de aprender com o cinema. Rio de Janeiro: Booklink, 2007. (Coleção Cinema e Educação).

FRESQUET, Adriana (Org.). Cinema e Educação: reflexões e experiências com professores e estudantes de educação básica, dentro e "fora" da escola. Belo Horizonte: Autêntica Editora, 2013. (Coleção Alteridade e Criação, 2).

FRESQUET, Adriana. Princípios e propostas para uma introdução ao cinema com professores e estudantes: a experiência do CINEAD/UFRJ. In: BARBOSA, Maria Carmen Silveira; SANTOS, Maria Angélica dos. (Org.). Escritos de alfabetização audiovisual. Porto Alegre: Libretos, 2014.

GLAT, Rosana. Educação inclusiva para alunos com necessidades especiais: processos educacionais e diversidade. In: LONGHINI, M. D. (Org.). $O$ uno e o diverso na educação. Uberlândia: EDUFU, 2011.

GOFFMAN, Erving. Estigma: notas sobre a manipulação da identidade deteriorada. Rio de Janeiro: Zahar, 1963.

JANUZZI, Gilberta. A luta pela educação do deficiente mental no Brasil. São Paulo: Autores Associados, 1992.

KASSAR, Mônica. A escola como espaço para diversidade. Educação $e$ Sociedade, Campinas, v. 37, n. 137, p. 1223-1240, out./dez. 2016.

KENSKI, Vani Moreira. Educação e tecnologias: o novo ritmo da informação. Campinas-SP: Papirus Editora, 2007.

LARROSA BONDÍA, Jorge. Notas sobre a experiência e o saber de experiência. Tradução de João Wanderley Geraldi. Revista Brasileira de Educação, Rio de Janeiro: Autores Associados, n. 19, p. 20-28, abr. 2002.

MAZZOTTA, Marcos José Silveira. Educação especial no Brasil: história e políticas públicas. São Paulo: Cortez, 1996.

MENDES, Enicéia Gonçalves. A radicalização do debate sobre inclusão escolar no Brasil. Revista Brasileira de Educação, v. 11, n. 33, p. 387-405, 2006. Disponível em: <http://www.scielo.br/pdf/rbedu/v11n33/a02v1133.pdf>. Acesso em: 11 set. 2016.

MINAYO, M. C. S. Pesquisa social: teoria, método e criatividade. Petrópolis: Vozes, 2006.

MIGLIORIN, Cezar. Cinema e escola, sob o risco da democracia. In: FRESQUET, Adriana (Org.). Dossiê cinema e educação \#1: uma relação sobre a hipótese de alteridade de Alain Bergala. Rio de Janeiro: UFRJ, 2011. 


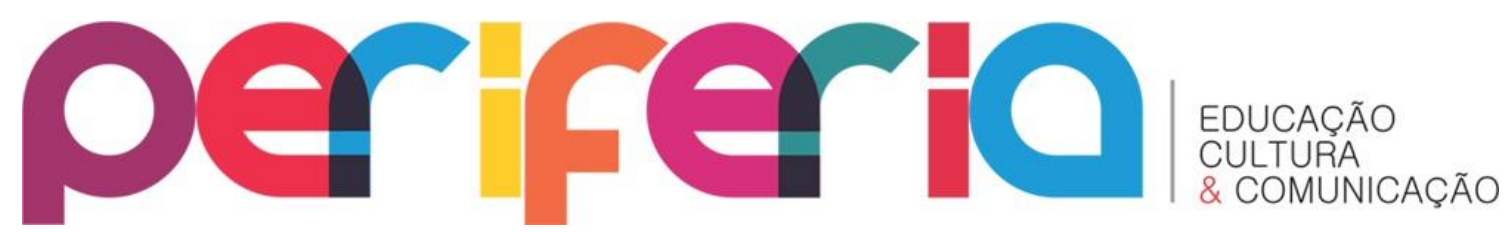

MIGLIORIN, Cezar. O cinema, a escola, o estudante e a invenção de mundos. In: BARBOSA, Maria Carmen Silveira; SANTOS, Maria Angélica dos. (Org. ). Escritos de alfabetização audiovisual. Porto Alegre: Libretos, 2014.

OMOTE, Sadao. Perspectivas para conceituação da deficiência. Revista Brasileira de Educação Especial, Piracicaba, v. 2, n. 4, p. 127-135, 1996.

PICCOLO, Gustavo Martins. Contribuições a um pensar sociológico sobre a deficiência. 2012. Tese (Doutorado em Educação) - Universidade Federal de São Carlos, São Carlos-SP, 2012.

PLETSCH, Márcia Denise. Repensando a inclusão escolar de pessoas com deficiência mental: diretrizes políticas, currículo e práticas pedagógicas. 2009. Tese (Doutorado em Educação) - Universidade do Estado do Rio de Janeiro, Rio de Janeiro, 2009.

PLETSCH, Márcia Denise. A escolarização de pessoas com deficiência intelectual no Brasil: da institucionalização às políticas de inclusão (19732013). Arquivos Analíticos de Políticas Educativas. Dossiê Educação Especial: diferenças, currículo e processos de ensino e aprendizagem, v. 22, n. 81, 2014.

TEIXEIRA, Inês Assunção de Castro; GRAMMONT, Maria Jaqueline de. Filmografia sobre os sujeitos e suas ditas deficiências: pensando o pensamento. Revista Teias, v. 17, n. 47, jan./mar. 2016.

THIOLLENT, Michel. Metodologia da pesquisa-ação. 14. ed. São Paulo: Cortez, 2005.

VYGOTSKI, Lev. Semenovitch. Obras escogidas V: fundamentos de defectología. Madrid: Machado Grupo de Distribuición, S. L., 2012.

VIGOTSKI, Lev Semenovitch; LURIA, Alexander Romanovich; LEONTIEV, Alexis Nikolaevich. Linguagem, desenvolvimento e aprendizagem. Tradução Maria da Penha Villalobos. 14. ed. São Paulo-SP: Ícone, 2016.

\section{FILMOGRAFIA}

A BELA e a Fera. Direção de Bill Condon. EUA, 2017 (2h19min).

FAMÍLIA Bélier. Direção de Eric Lartigau. França, 2014 (1h46min).

HOJE eu quero voltar sozinho. Direção de Daniel Ribeiro. Brasil, 2014 (1h36min).

LUZES da cidade. Direção, roteiro e produção de Charles Chaplin. EUA, 1931 (1h27min). 


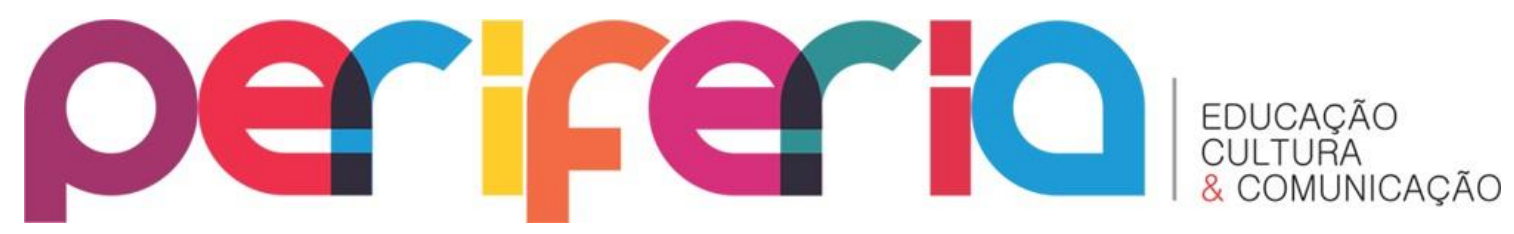

MOGLI: o menino lobo. Direção de Jon Favreau. EUA, 2016 (1h51min).

QUATRO vidas de um cachorro. Direção de Lasse Hallström. EUA, 2017 (2h). 